\title{
Living kidney donation and reasons for denial: A report from a Brazilian single-center cross-sectional study
}

\author{
Anna Lima ${ }^{1}$ (D), Lúcio R. Requião-Moura2,3 iD), Melissa Gaspar² iD, José Medina-Pestana2,3 iD \\ ${ }^{1}$ Nephrology department, Hospital Professor Doutor Fernando Fonseca, Lisbon, Portugal \\ 2 Department of Transplantation, Hospital do Rim, Fundação Oswaldo Ramos, São Paulo, SP, Brazil \\ 3 Department of Medicine, Nephrology Division, Federal University of São Paulo, SP, Brazil
}

\section{ABSTRACT}

Chronic kidney disease is increasingly more prevalent worldwide, and kidney transplant remains the best option for patient survival. Living kidney transplants (LKT) pose advantages over deceased donor transplants, such as longer graft survival, lower ischemia time, and better HLA match. However, LKT is not always attainable for multiples reasons, with the absence of a suitable living donor being a significant barrier. Therefore, meticulous donor screening must be performed in order to guarantee donation safety. We examined medical appointments of living kidney donors evaluated at Hospital do Rim, São Paulo, between January and December 2020. Reasons for not proceeding with the donation were evaluated and were categorized as medical, surgical, immunological, psychosocial, or other. A total of 506 donor-receptor pairs were enrolled for evaluation during the study period. More than half of screened donor-receptor pairs ( $\mathrm{N}=296,58.5 \%)$ were not considered feasible for LKT. The primary cause for refusal was medical contraindication (32.1\%), followed by immune (21.3\%) and social (19.3\%) causes. In addition, a considerable proportion of patients voluntarily withdrew themselves at variable time points during the evaluation process ( $\mathrm{N}=79$ ). In our center, most patients did not meet the criteria for kidney donation owing to medical reasons, similarly to other centers, and this reflects the importance of meticulous donor screening. In addition, the current Covid-19 pandemic affected the living transplant program, contributing to delayed complete donor and receptor evaluation.

Key words: Kidney donor denial, Kidney transplant, Living kidney donation

C 2021 Portuguese Journal of Nephrology \& Hypertension. Published by Publicações Ciência \& Vida This is an open access article under the CC BY-NC-ND license (http://creativecommons.org/licenses/by-nc-nd/4.0/).

\section{INTRODUCTION}

Chronic kidney disease is increasingly more prevalent worldwide. Many options are available for patients who progress to end-stage kidney disease (ESKD), but a kidney transplant remains the best option for patient survival ${ }^{1}$. Regarding transplant type, living kidney transplants (LKT) have advantages over those performed with deceased donors ${ }^{2,3}$, such as longer graft survival, lower ischemia time, better HLA match, as well as the possibility for preemptive transplant and decreased waiting time on the transplantation list. Furthermore, a faster transplantation allows better control of complications associated with ESKD, such as cardiovascular disease and mineral bone disease, and better patient survival ${ }^{4}$.

Although it has many advantages, LKT is not always attainable for multiple reasons. The main barrier is the absence of a suitable living donor, especially in families with genetic kidney disease. Despite donor availability, a meticulous evaluation has to be performed to assess the safety of kidney donation ${ }^{5}$. Evaluation for kidney donation encompasses multiple clinical aspects ${ }^{5}$ : screening for kidney disease and other chronic diseases that may put donors at risk for CKD after donation, evaluation of immunological compatibility, exclusion of anatomical contraindication for nephrectomy, and careful psychosocial evaluation. Depending on country regulation or center availability, performing ABO HLA incompatible or kidney paired donation may be an option ${ }^{6}$. Also, country regulation may impose donor-related transplants, as is the case in our center, where a transplant is performed only between relatives of first, second, third, or fourth-order and between spouses. For deceased donors, the consent regarding organ donation is attributed to the donor's family (or their legal representative). In Brazil, donation from non-heart-beating donors is not permitted; only after brain death. Living kidney donation also must be made freely with no coercion and not subject to financial benefit, as established by the Istanbul declaration?.

Consequently, a substantial proportion of patients screened for living kidney donation are not accepted as candidates for many reasons ${ }^{8,9}$. Herein, aiming at identifying primary reasons for donor rejection, we reported our experience regarding acceptance or rejection of living kidney donor candidates at Hospital do Rim (HRim) (São Paulo - Brazil), which is a world leader in kidney transplantation ${ }^{10}$. 


\section{METHODS}

\section{Study design and site}

This is a retrospective, observational, and descriptive cross-sectional study carried out at HRim. Data of medical appointments of living kidney donors evaluated at our center between January and December 2020 were included. Hospital do Rim is a high-volume transplant center in Brazil and worldwide ${ }^{10}$, where more than 1,000 patients were transplanted in $2015^{11}$, and LKT is an important part of the transplant program.

Reflecting the national transplant program, most patients are transplanted at HRim from a deceased donor ${ }^{12}$. In the last year, the percentage of LKT was about $25-30 \%$. An efficient program is established at the hospital to optimize medical and psychosocial evaluation and necessary laboratory exams or evaluations by other medical specialties to determine whether potential donors are suitable for $\mathrm{LKT}^{10}$.

\section{Approach for living kidney donation}

At HRim, LKD evaluation follows a comprehensive multi-step approach: a complete medical history and physical examination are performed to exclude any major contraindication on the first appointment. After that, blood collection for ABO, HLA compatibility and crossmatch are performed. In the second appointment, if crossmatch is negative, another subset of exams is requested: general blood test routines including screening for infectious diseases (HIV, HCV, HBV, CMV, syphilis, and Chagas disease), urine exam (24h collection for determining creatinine clearance and proteinuria, as well as urinalysis) and chest X-ray. If all exams are unremarkable, at the third appointment a contrast abdominal CT scan is requested for kidney anatomical and vascular evaluation. Depending on exam results and medical history, other exams or specialty evaluations may be requested at any time during this process. Also, all donors are screened for neoplasia according to the general population screening programs. Simultaneously, the recipient is screened for suitability for kidney transplantation and maintains his place on the waiting list ${ }^{13}$.

Established contraindications for LKD at HRIM are the presence of CKD, diabetes mellitus, hypertension with target organ damage or treatment requirement with more than two antihypertensive agents, cardiovascular disease, body mass index (BMI) $>35$, young donor age (less than 25 years old), nephrolithiasis (recurrent or bilateral), active neoplasia (or previous history of melanoma, monoclonal gammopathy, testicular, renal, pulmonary, gastrointestinal or breast cancer), active chronic viral infection (HIV, HBV, HCV, and HTLV) and drug abuse. Moreover, at HRim, the donation from sons to parents is not performed. Other relative contraindications are individualized according to the patient's clinical situation and the risk threshold acceptable for the center ${ }^{13}$. Donor voluntary withdrawal is available during evaluation and, if requested, a medical excuse not to donate is given.

Brazil has a very robust national and public health system that supports most treatments for chronic kidney disease, such as the dialysis system and the transplant program. The public health system covers all Brazilian citizens, so cost is not a restriction for transplantation.

\section{Variables of interest and Statistical analysis}

Reasons for not proceeding with the donation were evaluated and were categorized as medical, surgical, immunological, psychosocial, or other. Descriptive statistics and variable frequency were performed.

\section{RESULTS}

A total of 506 donor-receptor pairs were enrolled for evaluation during the study period. However, a considerable proportion of patients voluntarily withdrew themselves at variable time points during the evaluation process, a total of 79 (15.6\%): 47 not showing up for the initial interview and 32 during ongoing evaluation.

Other reasons for evaluation discontinuation were deceased donor transplantation $(\mathrm{N}=24,4.7 \%)$ and receptor death $(\mathrm{N}=1,0.2 \%)$. About $53(10.5 \%)$ of the donor-receptor pairs are on ongoing evaluation (mainly pending exams, evaluation by other medical specialties or reversible contraindications) and 85 patients (16.8\%) were accepted for donor nephrectomy (Table 1).

\section{$\underline{\text { Table } 1}$}

Patients enrolled for screening

\begin{tabular}{l|c}
\multicolumn{2}{c}{ Patients evaluated N=506 } \\
\hline Unfeasible Living Kidney donation & $296(58.5 \%)$ \\
Donor suitable for donation & $85(16.8 \%)$ \\
Pending evaluation & $53(10.5 \%)$ \\
Receptor submitted to deceased KT & $24(4.7 \%)$ \\
Receptor Death & $1(0.2 \%)$ \\
Renunciation & $47(9.3 \%)$
\end{tabular}

\section{REASONS FOR DONOR REJECTION - CHARACTERIZATION}

More than half of screened donor-receptor pairs ( $N=296,58.5 \%$ ) were not considered feasible for LKT. Regarding this group of patients, the reasons for not proceeding to LKT are shown in Table 2. The primary cause for denial was medical contraindication ( $N=95,32.1 \%)$ followed by immune ( $N=63,21.3 \%)$ and social $(N=50,19 ., 3 \%)$ causes. Of note, 17 (5.7\%) donors had a positive screening for CKD, either because of abnormal urine sediment or decreased measured creatinine clearance. Surgical causes for denial were related to complex vascular anatomy, mainly the presence of multiple arteries and/or veins and the decision to not procced with donation was always discussed with the surgical team. A total of 50 evaluated pairs were considered infeasible for LKD due to receptor contraindication ascertained during LKD evaluation. Other causes include donor religion precluding blood transfusion, a donation from son to parent (which is not performed at our center) and a prioritized recipient. 


\section{Table 2}

Causes for Living kidney transplant denial

\begin{tabular}{l|c}
\multicolumn{2}{c}{ Causes for denial (N=296) } \\
\hline Immune causes & $\mathrm{N}=63(\mathbf{2 1 . 3 \% )}$ \\
- Positive cross match & $50(16.9 \%)$ \\
- Incompatible ABO & $13(4.4 \%)$ \\
Medical causes & $\mathrm{N}=\mathbf{9 5}(\mathbf{3 2 . 1 \% )}$ \\
- Obesity & $31(10.5 \%)$ \\
- Chronic disease other than CKD & $8(2.7 \%)$ \\
- Nephrolithiasis & $22(7.4 \%)$ \\
- Diabetes mellitus & $7(2.4 \%)$ \\
- Hypertension & $10(3.4 \%)$ \\
- CKD & $17(5.7 \%)$ \\
Surgical contraindication & $\mathrm{N}=\mathbf{7}(\mathbf{2 . 3 \% )}$ \\
Social causes & $\mathrm{N}=50(\mathbf{1 6 . 9 \% )}$ \\
- Screening abandonment & $32(10.8 \%)$ \\
- Unrelated donor & $12(4.1 \%)$ \\
- Drug addiction (donor and/or receptor) & $6(2.0 \%)$ \\
Other & $\mathrm{N}=\mathbf{8 1}(\mathbf{2 7 . 4 \% )}$ \\
- Young age (<25 years old) & $11(3.7 \%)$ \\
- Other & $15(5.1 \%)$ \\
- Risk of primary disease recurrence & $5(1.7 \%)$ \\
- Unsuitable receptor & $50(16.9 \%)$ \\
Total & $\mathbf{2 9 6}$
\end{tabular}

\section{DISCUSSION}

Living kidney donation is a safe ${ }^{15}$ procedure, but donor selection and evaluation must be performed in a meticulous way ${ }^{5}$. Furthermore, studies have shown that the risk of CKD among donors is the same as in the general population but higher than in the healthy population $^{16,17}$. Nonetheless, ESKD in kidney donors is extremely rare and usually secondary to preventable causes (such as hypertension or diabetes $)^{15}$.

As CKD is becoming more prevalent, the gap between the need and availability of organs is increasing, and investment in LKT can aid in diminishing this gap. In addition, an increase in public awareness about living donation is crucial as a significant proportion of patients enrolled in the evaluation of kidney donation voluntarily withdrew or had medical contraindication for LKD, as seen in the data depicted above and in other similar data from centers worldwide . $^{8}$

Moreover, living donor transplants represent about $30 \%$ of all kidney transplants in Brazil, and this rate has decreased over the last 15 years. There is no kidney paired donation program thus all living donations are performed between relatives of first, second, third, or fourth order and between spouses. Although non-relative donor is allowed, this represents a low percentage of performed kidney transplants (only $7 \%$ in 2019, according to the Brazilian Registry of Transplantation) ${ }^{14}$. Since reports have shown that ESKD in living kidney donors is more frequently related to preventable causes, it is essential to provide them with continuous support in the donation process and during their lifetime after donation ${ }^{5}$. As such, follow-up at the transplantation center, general nephrologist, or at a primary care facility with easy access to the transplantation center is fundamental, and a post-donation care plan should be provided before donation ${ }^{5}$. Also, prioritizing transplantation for previous donors who evolve to ESKD is another essential practice. Since 2010, previous donors who evolve to end-stage kidney disease can be prioritized for deceased kidney transplant.

In our center, most patients did not meet the criteria for kidney donation because of medical reasons, similarly to other centers $(8,18)$, and this reflects the importance of meticulous donor screening. These medical contraindications relate to metabolic syndrome and related cardiovascular disease (such as obesity, diabetes mellitus, CKD and cardiac and vascular disease). It poses a big challenge for LKT programs as these diseases are increasing worldwide ${ }^{19-21}$ and, in a future perspective, will add further difficulty in kidney donor feasibility.

A possible opportunity for increasing LKT is to target public awareness and educational programs in order to try to diminish the proportion of potential donors that withdraw from the screening process. Further, immune causes constitute a considerable proportion for denial, in which paired donation programs and incompatible $A B O$ transplants could be a possible solution.

\section{Living kidney transplant program and Covid-19 pandemic}

Since 2020, with the Covid-19 pandemic, health programs were affected in various ways, with living kidney transplants being no exception. Many centers considered LKT as an elective procedure and suspended or reduced it, especially in the first wave of the pandemic, where little was known about the disease impact on transplant patients. Currently we already know that mortality is high among transplanted patients, as much as $25 \%^{22-24}$, and procedures were adopted in order to maintain transplantation a safe procedure (at HRim, in addition to clinical screening for respiratory symptoms, pre-operative nasopharyngeal Covid-19 PCR as well as thoracic CT scan are performed). Also, patients are instructed to maintain social distancing, mask use and frequent hand cleaning.

Of note, 53 of the enrolled patients (10.5\%) (donor or receptor) have pending issues regarding their evaluation; the majority exams or other specialized medical evaluation, which were significantly delayed because of the constraints regarding the Covid-19 pandemic. Also, screening abandonment after initial evaluation (donor and receptor) was high ( $\mathrm{N}=32,10.8 \%)$, which may be associated with the pandemic. In addition, HRim evaluates patients from all over Brazil and many restrictive measures adopted have made it difficult for patients to reach the hospital. For instance, the number of internal flights in Brazil was substantially reduced or even canceled in the initial phase of the pandemic.

Adopted measures varied according to the transplant center, although in the beginning, many centers opted for transplant program suspension (LKT or even both living and deceased donor transplant), especially in the first wave, or adapted the transplant program to make the transplant procedure safer. Nowadays we know much more about this disease and although an effective treatment is still not available, many are being researched and many vaccines are on the 
market. Nonetheless we still do not know the exact efficacy of the vaccine in immunosuppressed patients. Further, the pandemic is still not controlled, especially in countries which have vaccinated a small proportion of citizens only, and there could be several further waves of the epidemic before group immunity is reached. As such, it is essential to adopt measures to ensure safe maintenance of the transplant program from the initial screening of donor/receptor pairs (for instance telemedicine could help) to the transplant procedure itself.

Unfortunately, the number of living kidney transplants dropped drastically in 2020 due to the Covid-19 pandemic. Therefore, the results from the transplants performed over 2020 cannot represent all living kidney donations. In 2020, 116 kidney transplants were performed at Hospital do Rim. Among them, the 3- and 6-month patient survival was $100 \%$, and the 3 - and 6 -month graft survival was $99.1 \%$.

Our study has some limitations that should be pointed out. First, we used a tertiary source of information without access to medical records, which could introduce some bias, in addition to having a reduced amount of information available. Second, as discussed above, the transplant program was affected by the pandemic in different ways. Third, being a single-center study, some results may not reflect the same reality as other centers in our country. Last, due to cross-sectional analysis, we could not assess factors associated with the probability of each cause of donation denial. On the other hand, the high number of pairs enrolled in the present study is relevant and these pivotal results may drive further research.

In conclusion, most patients did not meet the criteria for kidney donation due to medical reasons, similarly to other centers, and this reflects the importance of meticulous donor screening.

Disclosure of potential conflicts of interest: none declared.

\section{References}

1. Abecassis M, Bartlett ST, Collins AJ, Davis CL, Delmonico FL, Friedewald JJ, et al. Kidney transplantation as primary therapy for end-stage renal disease: a National Kidney Foundation/Kidney Disease Outcomes Quality Initiative (NKF/KDOQITM) conference. Clin J Am Soc Nephrol. 2008;3(2):471-480.

2. Opelz G, Wujciak T, Döhler B, Scherer S, Mytilineos J. HLA compatibility and organ transplant survival. Collaborative Transplant Study. Rev Immunogenet. 1999;1(3):334-342.

3. Wang JH, Skeans MA, Israni AK. Current status of kidney transplant outcomes: dying to survive. Adv Chronic Kidney Dis. 2016;23(5):281-286.

4. Meier-Kriesche HU, Port FK, Ojo AO, Rudich SM, Hanson JA, Cibrik DM, et al. Effect of waiting time on renal transplant outcome. Kidney Int. 2000;58(3):1311-1317.

5. Lentine KL, Kasiske BL, Levey AS, Adams PL, Alberú J, Bakr MA, et al. KDIGO Clinical Practice Guideline on the Evaluation and Care of Living Kidney Donors. Transplantation. 2017;101(1):S1-S109.
6. Kranenburg LW, Visak T, Weimar W, Zuidema W, de Klerk M, Hilhorst M, et al. Starting a crossover kidney transplantation program in the Netherlands: ethical and psychological considerations. Transplantation. 2004;78(2):194-197.

7. Danovitch GM, Al-Mousawi M. The Declaration of Istanbul-early impact and future potential. Nat Rev Nephrol. 2012;8:358-361.

8. AlBugami MM, AlOtaibe FE, Boqari D, AlAbadi AM, Hamawi K, Bel'eed-Akkari K. Why potential living kidney donors do not proceed for donation: a single-center experience. Transplant Proc. 2019;51(2):504-508.

9. Lum EL, Shen JI, Beaumont JL, Treat E, Rastogi A, Waterman A, et al. Multiple reasons for living donor denial: a single-center experience. Clin Transplant. 2020;34(5):e13812.

10. Medina-Pestana JO. Organization of a high-volume kidney transplant program-the "assembly line" approach. Transplantation. 2006;81(11):1510-1520.

11. Medina-Pestana JO. More than 1,000 kidney transplants in a single year by the "Hospital do Rim" Group in Sao Paulo - Brazil. Clin Transpl. 2010:107-126.

12. Medina Pestana J. Excellence and efficiency through a structured large scale approach: the hospital Do Rim in São Paulo, Brazil. Transplantation. 2017;101:1735-1738.

13. Medina Pestana JO, Sandes Freitas TV, Silva Júnior HT. Transplante renal - manual prático, uso diário ambulatorial e hospitalar; 2014.

14. Transplantes RBd. Dimensionamento dos transplantes no Brasil e em cada estado (2013-2020); 2020.

15. Matas AJ, Berglund DM, Vock DM, Ibrahim HN. Causes and timing of end-stage renal disease after living kidney donation. Am J Transplant. 2018;18(5):1140-1150.

16. Muzaale AD, Massie AB, Wang MC, Montgomery RA, McBride MA, Wainright JL, et al. Risk of end-stage renal disease following live kidney donation. Jama. 2014;311(6):579-586.

17. Mjøen G, Hallan S, Hartmann A, Foss A, Midtvedt K, Øyen O, et al. Long-term risks for kidney donors. Kidney Int. 2014;86(1):162-167.

18. Connaughton DM, Harmon G, Cooney A, Williams $Y$, O'Regan J, O'Neill D, et al. The Irish living kidney donor program - why potential donors do not proceed to live kidney donation? Clin Transplant. 2016;30(1):17-25.

19. Hirode G, Wong RJ. Trends in the prevalence of metabolic syndrome in the United States, 2011-2016. Jama. 2020;323:2526-2528.

20. Longo A, Ribas BLP, Orlandi SP, Weber B, Bertoldi EG, Borges LR, et al. Prevalence of metabolic syndrome and its association with risk factors in patients with established atherosclerosis disease. An Acad Bras Cienc. 2020;92(1):e20180563.

21. Raposo L, Severo M, Barros H, Santos AC. The prevalence of the metabolic syndrome in Portugal: the PORMETS study. BMC Public Health. 2017;17(1):555.

22. Elias M, Pievani D, Randoux C, Louis K, Denis B, Delion A, et al. COVID-19 infection in kidney transplant recipients: disease incidence and clinical outcomes. J Am Soc Nephrol. 2020;31(10):2413$-23$.

23. Hilbrands LB, Duivenvoorden R, Vart P, Franssen CFM, Hemmelder MH, Jager KJ, et al. COVID-19-related mortality in kidney transplant and dialysis patients: results of the ERACODA collaboration. Nephrol Dial Transplant. 2020;35(11):1973-1983.

24. Thaunat O, Legeai C, Anglicheau D, Couzi L, Blancho G, Hazzan M, et al. Impact of the COVID-19 epidemic on the mortality of kidney transplant recipients and candidates in a French nationwide registry study (IMPORTANT). Kidney Int. 2020;98(6):1568-1577.

\section{ORCID}

Anna Lima (iD) 0000-0002-3937-7433

Lúcio Requião Moura (iD 0000-0001-8751-9048

José Medina Pestana (iD) 000-0002-0750-7360

Melissa Gaspar (iD 0000-0001-6908-1927

\section{Correspondence to:}

Lúcio R. Requião-Moura

Department of Transplantation, Hospital do Rim

R. Borges Lagoa, 960 - Vila Clementino, São Paulo - SP, 04038-002

Email: lucio.requiao@gmail.com 